\title{
TREATMENT AND PREVENTION OF CONSUMPTION IN COUNTRY TOWNS.*
}

\author{
BX JOHN R. STEINHAEUSER, M.B., B.S. Lond., \\ Medical Officer of Health for the Borough of Lewes.
}

Consumption has received so much attention of late years, has been so fully diseussed in all its bearings, and has been the target of every shaft which all the wit and ingenuity of men of sanitary science could devise, that it would be almost presumptious in me to attempt to add to the sum of knowledge or forge another weapon.

But I think that most of the enquiries into the subject, and the measures, proposed and adopted, for dealing with it, have been for the most part general so far as locality is concerned; and I have endeavoured in this paper to deal with the question in a specialized manner as regards the way in which it affects country towns. For I think there are special features in the latter which may possibly deserve attention.

The impression first given by a country town to a visitor versed in the knowledge of the causes of consumption would, I think, be that it was a place inimical to tuberculosis, a place to be shunned by that unclean spirit. The pleasant air, the cleanly streets, allowing vistas of open country with green fields and wooded slopes, the picturesque red-roofed houses, would give him a feeling of cheerfulness and health and security from disease. And this impression would be strengthened by the faces and appearance of the people he met: here a group of bronzed, hearty-looking farmers stand talking outside the Corn Exchange : there cricket team starting for an out-match from the hotel in the principal street, or a few people casually shopping: in everyone an absence of that hurry and bustle which is so characteristic of life in a large town, and which is, no doubt, conducive to disease.

Is Mortality Higher?-Enquiries might tell the visitor that the sanitary record of the town was good, that it was well scavenged and drained, that it was provided with a good water supply and efficient sanatorium for infectious diseases, that its incidence of enteric fever and infant mortality were low, and deaths from senile decay many; yet when, well satisfied, he came to look up statistics of mortality from tuberculosis, it is possible that he would find them, to his surprise, to equal, if not exceed, those for some of the industrial centres, at all events, those for the country at large.

* Paper read at a meeting of the Southern Branch of the Society of Medical Officers of Health, on March 25th, 1904. 
For here is an anomaly: one would expect to find a comparative immunity from tuberculosis in country towns. ipso facto, possessing all the advantages of country and town with the disadvantage of neither-i.e., abundance of pure air, fair drainage, good food supply as regards milk and meat, comparative absence of poverty and slums, and a fairly sanitary-intelligent community.

No doubt in some cases, as I have been able to ascertain, the deathrate is lower; this, however, often coincides with a low county rate, while in others the rate is really higher (from 1.5 to 1.9 per 1,000 ) than that for England and Wales.

To consider now the common causes of consumption so far as they affect country towns.

In most country towns there are many old houses-red-roofed, picturesque old houses-which are veritable death-traps; damp, badly lighted, badly ventilated, badly drained, sometimes back-toback, with rooms low pitched, devoid of fireplace; lattice windowsmade so as not to open-niggardly admitting a few rays of the sun which has looked down on the dying faces of successive consumptive tenants. Houses decaying, damp, and deadly. It is sad to visit a consumptive patient in such a house, in such a room. I have seen a mother lying in the last stage-emaciated, breathless, whose every frequent cough emitted a spray teeming with bacilli-with one of her children actually in bed with her, while the others were playing in the room.

As elsewhere, these houses play another part in furthering the incidence of consumption by driving men to the public-house. I may, perhaps, quote Professor Brouardel, who said at the Congress on Tuberculosis in London, 1901, "Unhealthy dwellings cause other disasters: dark and crowded as they are, cleanliness is difficult, if not impossible, to preserve ; they are not pleasant to pass the time in, and the workman stays in his home as little as possible: he eats there and sleeps there, but the rest of his time is spent in the publichouse. J. Simon was right in saying, "The wretched lodging is the purveyor of the public-house,' and we can add that the public-house is the purveyor of tuberculosis."

Inherited Tendency. - One finds a remarkable consanguinity amongst the inhabitants of country towns. There seems to be less tendency, than exists elsewhere, to emigrate to other districts. Consequently intermarriages in the sam somparatively limited community are frequent, and there is, thererore, a greater probability of any consumptive tendencies being handed down to posterity.

Alcohol.-I do not say that there is more intemperance in country towns, but there is an absence of facilities for evening amusement, 
which is not felt in large towns, and which, in default, brings men to the public-houses. Only too often, glad to get away from his uncomfortable cottage, the working man goes to his favourite beerhouse to drink and talk and incidentally expectorate. We know how large a part the public-house plays in the incidence of tuberculosis : first, because alcoholic excess is one of the chief predisposing causes; and, second, because the existing cause, the bacillus, is so frequently found there; since nowhere is expectoration so largely indulged in as in the crowded, dusty bars.

As a rule there are no particular dusty occupations in country towns; yet work places, e.g., printing offices, like dwelling houses, are often old, badly ventilated, and badly lighted.

Prevention and Treatment.-The treatment of consumption has as one of its aims the securing for the sufferer of fresh air (sterile, so far as it is possible, of tubercle organisms), and, from a consumptive's point of view, one of the chief advantages of a country town should be the facility with which he can obtain this blessing. In a town like Lewes, for example, surrounded as it is by downs, there should be no difficulty in the consumptive spending the whole day in the most excellent air, and during the warmer months there is no reason why he should not camp out during the night, thereby gaining health for himself and averting the polluting of his home which his presence therein entails. At the present time it is so difficult to persuade the less-informed classes as to the importance and harmlessness of fresh air, that treatment on these lines is seldom taken advantage of ; they err through ignorance. It would be an excellent thing if consumptives could be hunted up in the early stages, and induced to undergo treatment without waste of precious time.

Two measures could, I think, be easily and with little expense taken in every town.

1. Formation of a committee composed of benevolent men and women genuinely interested in prevention of tuberculosis, whose object it would be to visit the houses of the poor, find out any cases of chronic cough, debility, etc., and tactfully put them in the way of obtaining advice and treatment; also to look after their families while husband or wife were undergoing treatment. I am sure that a great work could be accomplished by district visitors alone, who, by making themselves acquainted with the well-known causes and means of prevention of tuberculosis, and armed with printed cards of instructions to that effect, could impart their knowledge to the poor people they visited, and ensure that the latter should not, through ignorance at all events, drift into advanced consumption. In work places the same function might be undertaken by foremen or fore- 
women. Alive to the danger of badly-kept workrooms, they would see that the latter were kept clean and as well ventilated as circumstances permitted; moreover, they could impress upon the employés under them the danger of neglected colds, and tell any sufferers where to seek advice.

2. Anti-Tubercular Dispensaries, as in France.-Such a dispensary could be easily and cheaply run in a country town. A couple of rooms in a cottage would be sufficient as waiting and consulting rooms, while the scullery could be fitted up as a dispensary. The mere fact of its institution would attract attention, and patients, who would receive necessary medical attention and be cautioned as regards dangers of communication of disease by sputum. If funds permitted they could be helped in the way of suitable food, and their homes, from a hygienic point of view, looked after.

The addresses of consumptive patients being thus known, rooms could be from time to time disinfected by the Sanitary Authority.

Sanatorium Treatment.-The difficulties met with in providing sanatoria for the poor are too obvious to require comment. The supply is fearfully inadequate to the demand. Many sanitarians have declared a really adequate provision to be impracticable; yet perhaps the difficulty of dealing with individual cases without such provision is really greater, and one only appreciated by the medical man-of-allwork. The poor consumptive, under existing conditions, obtains with much difficulty a letter of admission to one of the well-known free sanatoria, and then-even if accepted-finds he must wait ten or twelve weeks before he can hope to go into hospital ; meanwhile, he too often becomes so much worse as to be ineligible when his turn does come, or else dies.

In a small country town I think the institution of a sanatorium ought to be practicable. Here the inhabitants generally know something of each other, and more interest is probably taken in individual consumptives than in larger communities. And this being the case, I think the richer members are more willing to help their poor consumptive brethren, knowing something about them and their belongings and antecedents. I believe a site might be given by a benevolent landowner, and a hospital, containing four beds (for a town of 10,000 population), should not cost more than $£ 800$ to build and equip. This sum once obtained, two guineas per head per week should keep the establishment going. No patient would be admitted unless this sum were guaranteed (by his friends) and the hospital would be only available for the really indigent: for those in receipt of parish relief the Guardians might be reasonably expected to pay three instead of two guineas per week. 
I believe that such a sanatorium, for " clan " reasons which I have tried to explain, could be conducted upon very economic lines; that, for instance, neighbouring farmers would supply milk, butter, eggs, etc., at the lowest possible prices ; in its aid bazaars and entertainments would be organized and church offertories given.

Another alternative for a town so small would be-as in Westmoreland-an amalgamation with other town or towns. In this case the sanatorium would of course be larger, but with less cost per patient on that account.

Or a fund might be raised to retain one or more beds for the special needs of the town in some large, well-known sanatorium.

Hygiene should be taught in Elementary Schools.-The first step is of course to ensure that all classes of the community should thoroughly understand the causes working for consumption-which none can afford to ignore-and thus their co-operation might be gained. It is a national disease, and all classes should combine to resist it.

The few simple elementary rules of health, e.g., importance of cleanliness, ventilation, physical exercise, and temperance-the very safeguards against tuberculosis-should, without doubt, be specially taught in our elementary schools. A generation will then at last arise who, freed from the ignorance of its predecessors, will unite to throw off the yoke of consumption.

Failure of Laity to appreciate Consumption as Infectious Disease.Meanwhile, consumption as a communicable disease should be dealt with on the same lines as other infectious diseases. The apathy displayed by sanitary authorities in this respect is quite remarkable. In a small country town a single case of scarlet fever or diphtheria will create a small panic, whereas the fact that there are perhaps forty cases of consumption at the time produces little interest, certainly no alarm. It is significant that in one country town statistics for the year showed that there was not a single death from all the notifiable diseases put together, whereas from consumption there were nineteen.

Notification, in a country town at the present state of affairs, I regard as unnecessary. I think the Sanitary Authority should notify all medical men in the town that it is willing to disinfect, from time to time, free of charge, any rooms occupied by a consumptive tenant. In this way a knowledge of a very large proportion of the incidence of consumptive houses would be obtained and dealt with. Precautions as regards dangers of infection can, I think, be safely entrusted to the medical attendant, who is probably more likely than the sanitary official to exact obedience from his patient. I am persuaded that disinfection of rooms, i.e., thorough cleansing, washing 
and spraying of walls and ceiling with disinfectant, ought to be practised if possible at least every two months.

I have stated that I believe the condition of the houses of the working class-upon whom the incidence of consumption chiefly falls-to be the chief factor in keeping up the death-rate from consumption in many country towns; it is a condition which urgently demands improvement. And here we are in the hands of the Sanitary Authority and the landlord.

Improvement Scheme.-The most satisfactory way of dealing with some of the worst of these houses would be a comprehensive improvement or reconstruction scheme sanctioned by the Local Government Board. No doubt the financial burden imposed on a small town thereby would be very heavy and likely to meet with much opposition in a small community, which is often already heavily taxed. There would also be, in a small town, the difficulty of finding accommodation for the dispossessed tenants without causing overcrowding in other districts. However, such a scheme once effected, the thing would be done with for good and all. There would be an end to the everlasting supervision and tinkering up of decayed houses, which is all that the most active Sanitary Authority can otherwise accomplish, and which never fully effects the desired object.

House-to-house Inspection Committee.-Failing this it is necessary that all the meaner streets should receive seriatim a very rigorous inspection, and notices be served on owners to remedy all sanitary defects (amongst which should be included unopenable windows). In Lewes a Sub-Committee of the Sanitary Committee has been formed, called the House-to-House Inspection Committee, which, during the two years of its existence, has done really excellent work; thanks to its efforts many of the poorer houses have been drained or re-drained, cesspools and wells abolished, new w.c.'s have been provided, and portable ashbins supplied in place of the old ashpits.

Necessity for Radical Structural Alterations.-But, so far as consumption is concerned, it should be possible to go farther than this: to insist on radical structural alterations in houses needing them, such as provision for really sufficient light and ventilation, ensuring of damp-proofness, providing in all rooms a fireplace and chimney, removal of any obstructions to light and ventilation, etc.

Improved Housing by Private Enterprise.-In a country town wages are low, and low rents are therefore necessary. It is impossible for a man earning from $14 \mathrm{~s}$. to $16 \mathrm{~s}$. a week to pay much rent, and landlords are not likely to do more than they are obliged to a cottage only bringing in 3s. $6 \mathrm{~d}$. to $5 \mathrm{~s}$. weekly. At the same time, I am glad to say that in this town a certain amount of improvement of such property 
has been undertaken voluntarily by owners. Here, again, philanthropy might come to the aid of public health. A capitalist, content with 2 per cent on his outlay, could buy up old property, demolish it, and re-build quite good cottages at a rental of $4 \mathrm{~s}$. each weekly, and he would be rewarded by seeing the certain improvement in the health of the locality as the result of this action.

Insufficient Air-space in Workshops.-As regards factories and workshops in all places, I venture to give my opinion that 250 cubic feet minimum air space per worker is absolutely insufficient to secure 3,000 cubic feet of fresh air per hour per worker, except under the infliction of an unbearable draught. One so often finds in workrooms windows closed, ventilators pasted over even, and consequently exceeding stuffiness.

Touching alcohol, I think it most desirable that more efforts should be made to take people out of public houses, and that more entertainments should be organized in country towns. I may say that in Lewes social clubs in various parishes are doing good work in this respect, and that the younger men are really improved physically and mentally since these institutions have been started. Out-of-door recreations should be encouraged by institution of cricket and football clubs and athletic associations.

I have not dealt with soil and site and wind as causes affecting the incidence of tuberculosis, and I am not sure that the relation between them has been satisfactorily worked out. In this town I find that the incidence is quite as heavy in the upper and drier parts of the town as in the alluvial district near the river.

Advanced Consumptives.-These are the source of most danger, and are the most difficult to deal with. Their friends are naturally unwilling for them to go away to die, even if there were a hospital to receive them. All that can be done is to try to enforce isolation, so far as is practicable, in their homes; they should of course occupy one and only one room, which none else should share.

Steps taken for dealing with Consumption in various Country Towns.Through the kindness and courtesy of their Medical Officers of Health, I gather that :-

In most: Houses are disinfected after the death of consumptive tenant.

In several: Voluntary notification is practised.

In very few : Is there special sanatorium treatment.

To recapitulate measures to be taken :-

1. Committee for prevention of tuberculosis to visit, advise, and help financially consumptive patients.

2. Institution of dispensary, and subsequently, if funds permit, of sanatorium, under auspices of :- 
(a) Private generosity.

(b) Local Sanitary Authority.

(c) Local Poor Law Authority.

(d) Local Friendly Societies.

3. Instruction on elementary hygiene in senools.

4. Sanitary Authority to undertake periodical disinfection of rooms occupied by consumptives.

5. More strenuous exercise on part of Sanitary Authority of statutory powers, enabling them to deal with unhealthy areas and houses, and supervise workshops.

6. Legislation against spitting in public places.

7. Facilities for amusement, formation of social clubs, etc.

Finally, while sorrowfully admitting that I have shown you nothing new, that my observations are well-worn and commonplace, and suggestions often rather impracticable, I hold that the subject, at all events, of this paper is an all-important one, and one never to us devoid of interest; and $I$ hope-and that is my excuse for writing the paper at all-that from the discussion which may follow I may gather some crumbs of knowledge which will enable me in my own district to deal better with the difficulties of treatment and prevention of consumption in our pleasant country towns.

WE regret tohave to record the somewhat sudden death of Charles Kelly, M.D., F.R.C.P., Medical Officer of Health for West Sussex, at the age of fifty-nine. Dr. Kelly was for a number of years Professor of Hygiene in King's College, London.

General Medical Council.-The following report of the Public Health Committee was presented and adopted at the recent meeting :-

1. The Committee reported that it had considered a communication from the Advisory Board of the War Office, and had unanimously agreed to advise the Council to add to the present list of districts and commands recognized as suitable for the purpose of outdoor training in hygiene under Rule $3(e)$ of the Council's Resolutions and Rules for Diplomas in Public Health, the following additional military commands, namely: Madras, with a civil population of 72,000 ; Bengal, with a civil population of 38,000 ; and the Punjab, with a civil population of 42,000 .

The Committee had also considered an application from Dr. Pinching, Director-General of the Sanitary. Department of the Ministry of Interior of Egypt, for recognition as competent to give the certificates required by Rule 3. The Committee recommended that this application should not be granted. The Sanitary Department of the Ministry of Interior Egypt, is not under the control of the Director-General of the British Army Medical Department, and is in no sense comparable with the districts and commands as defined in Rule $3(e)$ of the Council's Resolutions and Rules for Diplomas in Public Health. 